\title{
Erratum to: A desirability function-based scoring scheme for selecting fragment-like class A aminergic GPCR ligands
}

Ádám A. Kelemen · György G. Ferenczy •

György M. Keserü

Published online: 14 November 2014

(C) Springer International Publishing Switzerland 2014

Erratum to: J Comput Aided Mol Des

DOI 10.1007/s10822-014-9804-5

The following was inadvertently missing from the acknowledgements. Acknowledgment Financial support for this work has been
provided by the Grant KTIA-NAP-13-1-2013-0001.

The online version of the original article can be found under doi:10.1007/s10822-014-9804-5.

\footnotetext{
Á. A. Kelemen · G. G. Ferenczy · G. M. Keserü ( $\square)$ Medicinal Chemistry Research Group, Research Centre for Natural Sciences, Hungarian Academy of Sciences, Magyar, Tudósok Körútja 2, Budapest 1117, Hungary

e-mail: keseru.gyorgy@ttk.mta.hu
} 